\title{
Marcus Aurelius ve Lucius Verus Dönemlerinde M.S. 165-180 Yılları Arasında Görülen Büyük Salgın
}

\section{Pandemic Under Marcus Aurelius and Lucius Verus Between A.D. 165-180}

\author{
Mustafa Hamdi Sayar* (1)
}

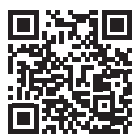

*Prof. Dr., İstanbul Üniversitesi, Edebiyat Fakültesi, Tarih Bölümü, İstanbul, Türkiye

\section{ORCID: M.H.S. 0000-0001-6339-9002}

Sorumlu yazar/Corresponding author: Mustafa Hamdi Sayar,

İstanbul Üniversitesi, Edebiyat Fakültesi, Tarih Bölümü, İstanbul, Türkiye

E-posta/E-mail: mhsayar@istanbul.edu.tr

Başvuru/Submitted: 17.06.2020 Revizyon Talebi/Revision Requested: 01.07.2020

Son Revizyon/Last Revision Received: 08.07.2020

Kabul/Accepted: 12.07 .2020

\section{Atıf/Citation:}

Sayar, Mustafa Hamdi. "Marcus Aurelius ve Lucius Verus Dönemlerinde M.S. 165-180 Yılları Arasında Görülen Büyük Salgın." Tarih Dergisi - Turkish Journal of History, 71 (2020): 15-28.

https://doi.org/10.26650/TurkJHist.2020.002

\section{Öz}

162 yılında Lucius Verus komutasında başlayan Parth seferi sırasında 165 yılında Nisibis'te görülmeye başlayan salgın esnasında sefere katılan askeri birlikler, imparatorluğun Balkanlar ve Avrupa bölgelerinde konuşlanmış bulunuyorlardı. 162 yılından 166 yılına kadar süren Parth seferine katılan askerlerin Ren ve Tuna sınırlarındaki sürekli konuşlandırılmış oldukları karargâhlarına dönmeleriyle birlikte salgın Avrupa'ya ve hatta Britannia'ya kadar taşındı. Bu durum Marcus Aurelius dönemindeki salgında oluşan kayıpların kesinlikle abartılmadığını oldukça yüksek can kaybı olduğunu, imparatorluğun sınırları içerisindeki nüfus yapısının önemli ölçüde etkilendiğini ve hastalığın yarattığı tahribatın dönemin kaynaklarında da belirtildiği gibi yıllarca sürdüğünü, hatta Roma sınırları dışında Barbaricum bölgesine de yayıldığını ortaya koymakta; belki Marcus Aurelius'un yerine geçen oğlu Commodus zamanında da devam etmekte olduğunu düşündürmektedir. Ne M.Ö. 430/429 yılında Atina ve çevresinde görülen salgının ve ne de M.S. 248 yılında Roma imparatorluğunda görülen ve Decius ya da Kyprianos salgını olarak tanımlanan hastalığın yayıldığı alan bu kadar büyük değildi ve bu kadar yüksek sayıda can kaybı yoktu. 6. yy. da Justinianus döneminde dalgalar halinde yayılan ve Justinianus vebası olarak tanımlanan veba salgını yıllarca kitlesel ölümlere neden olmuş ve neredeyse Ortaçağda görülen büyük veba salgınları gibi o zaman için bilinen dünyanın nüfus yapısının değişmesine neden olacak ağır can kayıpları meydana gelmişti. 19. yy.da bazı eskiçağ tarihçileri Antoninus salgını olarak bilinen Marcus Aurelius dönemindeki salgının yarattığı yıkıcı etkinin Roma imparatorluğunun 3 . yy.da yaşadığı, siyasi, asker ve iktisadi krizin hazırlayıcısı olduğunu hatta eskiçağın bitimi olarak yorumlanabileceğini öne sürmektedirler. Ancak Roma imparatorluğunun 3. yy.da yaşadığı krizin 2. yy.ın ikinci yarısındaki Antoninus salgınının yarattığı olumsuzluklardan başka nedenleri de vardı.

Anahtar sözcükler: Lejyon, sefer, bölgelerüstü salgın, belirti, bölgelerarası hareketlilik

\section{ABSTRACT}

A pandemic began to occur in Nisibis in AD 165 during the Parthian expedition, which began in AD 162 under the command of Lucius Verus. Military troops which had their headquarters stationed in the Balkans and in the European 
regions of the empire, were involved in the Parthian expedition and suffered under this pandemic. The epidemic then moved further into Europe and even to Britannia, as the soldiers who had participated in the expedition from AD 162 to AD 166 later returned to their headquarters at the borders of the Rhine and Danube. The losses which occurred as a result of the epidemic in the period of Marcus Aurelius were not exaggerated. The death toll was very high and the population structure within the borders of the empire was significantly affected. The destruction caused by the disease continued for years, as stated in the sources of the period. According to these sources, the disease even spread to the Barbaricum region outside the borders of Rome and also continued during the period of Commodus who reigned immediately after his father Marcus Aurelius. Neither the epidemic which had occurred in 430-429 BC in the vicinity of Athens, nor that of AD 248 in Rome (also called Decius or Kyprianos), spread to such a vast area as the pandemic of AD 165, and the death toll of these other epidemics was not as high as that of AD 165. By comparison, the Plague of Justinianus in the 6 th century spread in waves and caused many deaths for years. Like the plagues of the medieval period it changed the populational structure of the world. In the $19^{\text {th }}$ century ancient historians argued that the destructive effect of the pandemic of Marcus Aurelius' era, also known as "The Antoninus Epidemic", caused the political, military and economic crisis that the Roman Empire faced in the $3^{\text {rd }}$ century and it could even be interpreted as the end of Antiquity. However, there were other reasons for this crisis in the $3^{\text {rd }}$ century, and it is notable that the negative effects of the pandemic were mainly seen in the second half of the $2^{\text {nd }}$ century.

Keywords: Legio, expedition, pandemie, symptom, intrerregional mobility

M.S. 162 yılında Roma imparatorluğu uzun zamandır savaşmakta olduğu Parth krallığına karşı yeni bir askeri harekata başladı. Roma imparatorluğunu M.S. 161 yılında ölen imparator Antoninus Pius'un yerine geçen imparator Marcus Aurelius ve tıpkı onun gibi Antoninus Pius tarafından evlat edinilmiş olan Lucius Verus birlikte yönetmekteydiler ${ }^{1}$. 162 yılında başlayan Parth seferinin komutasını Lucius Verus üstlenmişti². Verus'un harekatın komuta merkezi olarak kullandığı Antiokheia'dan (=Antakya) yönettiği harekât büyük ölçüde başarılı oldu ${ }^{3}$ Ren ve Tuna sınırlarından Anadolu'ya sevk edilen üç lejyon, Kappadokia valisi Statius Priscus'un komuta ettiği Legio V Macedonica, Legio II Adiutrix ve Legio I Minervia, Romalılar ve Parthlar arasında tampon bölgeyi işgal ederek ve özellikle

1 Antoninus Pius'un, Marcus Aurelius ve Lucius Verus'u evlat edinme süreci ve bu kararları almasının zamanlaması ve gerekçeleri hakkında bkz. Chr. Michels, "Antoninus Pius und die Rollenbilder des Römischen Princeps", Klio Beiheft, No. 30, Berlin 2018, s. 22-25.

2 SHA, Verus 4-6; K. H. Ziegler, Die Beziehungen zwischen Rom und dem Partherreich. Ein Beitrag zur Geschichte des Völkerrechts, Wiesbaden 1964; K. Schippmann, Grundzüge der parthischen Geschichte, Darmstadt 1980; K. Strobel, "Zeitgeschichte unter den Antoninen Die Historiker des Partherkrieges des Lucius Verus", Aufstieg und Niedergang der römischen Welt. Geschichte und Kultur Roms im Spiegel der neueren Forschung, ed. Wolfgang Haase, Teil II: Principat, Band 34/2 Berlin 1994, 1315-1360; G. Bowersock, "Lucius Verus in the Near East", Rome et ses provinces. Génèse et diffusion d'une image du pouvoir, ed. C. Evers - A. Tsingarida, Hommage à J.-Ch. Balty, Bruxelles 2001, s. 73-77; P. Edwell, Between Rome and Persia, The Middle Euphrates, Mesopotamia and Palmyra under Roman Control, London 2008; J. Fündling, "Lucius Verus, Seine Lobredner, seini Kritiker und sein Platz in der Herrschaft"; Studien zur antiken Geschichtsschreibung, ed. M. Rathmann, Antiquitas 1. 55. Bonn 2009, 211-236; M. C. Bishop, Lucius Verus and the Roman Defence of the East, South Yorkshire 2018; A. Demandt, Marc Aurel, Der Kaiser und seine Welt, Münih 2018, 148-149.

3 Lucius Verus'un Antiokheia'yı karargâh olarak kullanması ile yaklaşık 50 yıl evvel yine Parthlara karşı yapılan seferde imparator Traian'ın Antiokheia'yı karargâh olarak kullanması arasındaki yapısal benzerlikler hakkında bkz. A. Gebhardt, "Imperiale politik und provinziale Entwicklung. Untersuchungen zum Verhältnis von Kaiser Heer und Städten im Syrien in vorseverischer Zeit", Klio Beiheft, Neue Folge 4, Berlin 2002, s. 152-155. 
Elegeia ${ }^{4}$ ile stratejik Artaxata şehirlerini ${ }^{5}$ ele geçirerek daha sonra Parth ülkesinin merkezine yapılacak harekatın kuzeyden güvenceye alınmasını sağladılar6́ 164 yılında Antiokheia'da bulunan Lucius Verus, ileri harekâtı başlatmaya karar verdi ve Avidius Cassius komutasında taarruza geçen Roma lejyonları Edessa (=Urfa) ve Carrhae (=Harran) şehirlerini ele geçirdiler ${ }^{7}$. Edessa'dan doğuya doğru ilerleyen Roma birlikleri o dönemde ormanlık bir arazi içinde bulunan Nisibis'e (Nusaybin) ulaşarak büyük stratejik önemi olan Nisibis’i uzun süren çatışmalar sonucunda ele geçirebildiler ${ }^{8}$. Nisibis yüzyıllar boyunca Parthlar ile Romalılar arasında sık sık çatışmalara sahne olan bir sınır garnizonu oldu' . Avidius Cassius Parth kralı Vologaeses'i yenerek bölgeden geri çekilmek zorunda bıraktı ${ }^{10}$. Roma birlikleri güneye doğru ilerleyerek Fırat nehri batı kıyısındaki stratejik öneme sahip Dura-Europos şehrini ele geçirdiler. Böylece Babil'den Palmyra'ya ve oradan da Suriye'ye uzanan ticaret yolunun denetimi Roma ordusuna geçmiş oldu. Daha güneyde Birtha üzerinden Sura kalesine ulaşan Roma birlikleri burada gemilerden oluşturdukları bir köprü ile Fırat nehrinin doğu kıyısına geçtiler ${ }^{11}$. Bugün Bağdat şehrinin bulunduğu bölgenin güneyinde Dicle ırmağı batı kıyısında yer alan ve Seleukos krallığının eski başkenti olan Seleukeia şehrine vardılar ${ }^{12}$. Seleukeia şehri ile karşı kıyıda nehrin doğu yakasında bulunan Parth'ların başşehri Ktesiphon Roma birlikleri tarafından ele geçirildi ${ }^{13}$. Parth kralı IV. Vologaises'in karargâh olarak kullandığı kaleyi yakarak tahrip etmişlerdi ${ }^{14}$. Bu sırada Romalı askerler bir Apollon Komaeos tapınağına girmişler ve Apollon heykelini ganimet olarak alıp Roma'daki Apollon tapınağına sunmak üzere beraberlerinde götürmüşlerdi ${ }^{15}$. Ayrıca yağma sırasında tapınağın adyton kısmında buldukları dar bir açıklıktan girdiklerinde uzun zamandır açılmamış olan ve içinde niteliği bilinmeyen bir madde olan eski bir mahfaza (=labes primordialis) kırılmış ve içinden spiritus pestilens = salgın ruhu olduğuna inanılan bir duman havaya yayılmıştı ${ }^{16}$. Bu maddeden yayılan mikropların bulaştı̆̆ Roma'ya ve İtalya'ya yaydıkları ve oradan da Gallia'ya ve Britannia'ya kadar bu hastalığın

\footnotetext{
4 Erzurum'un batısında yer almaktadır.

5 Erivan'ın yaklaşık $20 \mathrm{~km}$ güneyinde Artaşat ören yeri.

6 Bkz. Ekteki harita.

$7 \quad$ Lukian, Historia 22.

8 Cassius Dio 68, 26, 1; Nisibis 363 yılında Sasanilerin eline geçti; 1260 yılında Moğol hükümdarı Hülâgû'nun yıkımına uğradı.

9 Ammianus Marcellinus 25, 8, 14.

10 Cassius Dio 71, 2, 3.

11 Cassius Dio 71, 3, 1 .

12 Bölgeye 116 yılında ulaşan imparator Traian buradaki yerleşmeleri Parth'ların barınmamaları için yaktırmıştı. Cassius Dio 68, 30, 2. Bkz. Ekteki harita.

13 Cassius Dio 71, 2.

14 Cassius Dio 23, 6, 24.

15 Bu olay hakkında ayrıntılı bilgi ve önceki yayınlar hakkında bkz. H. Klinkott, "Parther-Pest-Pandoramythos Katastrophen und ihre Bedeutung für die Regierungszeit von Marc Aurel"; Marc Aurel. Wege zu seiner Herrschaft, ed. V. Grieb, Gutenberg 2017, s. 285-305.

16 Ammianus Marcellinus 23, 6, 24.
} 
yayıldığg iddia edilmektedir ${ }^{17}$. Oysa bu yağmalama öncesinde Seleukeia'da salgının zaten başlamış olduğu öne sürülmektedir. Bu önemli askeri başarıları kazanan Roma ordusu salgın hastalık ve açlıktan kırılmasına rağmen güçlükle Suriye'ye geri dönebildi ${ }^{18}$. 165 yılı sonbaharında sona eren Parth seferinin muzaffer komutanı Lucius Verus doğu cephesini büyük ölçüde güvene almış olarak 166 yılı yazında İtalya’ya geri döndü ve 12 Ekim günü Marcus Aurelius ile birlikte görkemli bir zafer alayıyla Roma şehrine girdi ${ }^{19}$. Roma devleti Parthlara karşı kazandığı zaferle büyük bir güç olduğunu göstermişti. Ancak Romalıların hesaba katmadıkları bir olumsuzluk vardı. Kazandıkları bu büyük Parth zaferi için çok büyük bir bedel ödeyeceklerini zaman gösterecekti² ${ }^{20}$.

Parth seferine katılan askeri birliklerin mensuplarında ağır hastalık belirtileri görülmeye başladi ${ }^{21}$. Hastalanmaya başlayanların sayısının hızla artmasıyla birlikte Roma ordusundaki askeri doktorlar bu durumun nedenini araştırmaya başladılar ve yayılan hastalık ile Parth seferi arasında doğrudan bir ilişki olduğunu belirlediler ${ }^{22}$. Aslında salgının ilk belirtileri Nisibis'te (=Nusaybin/Mardin) konuşlanmış olan lejyon birliğinin askerleri arasında bir yıl önceden, 165 yılında görülmeye başlamıştı. Parth seferine katılan lejyonların Ren ve Tuna sınırlarındaki asli karargahlarına dönmeleriyle birlikte salgın Avrupa'ya taşındı. 162 yılından 166 yılına kadar süren Parth seferine katılan askeri birlikler, imparatorluğun çeşitli bölgelerinde konuşlanmışlardı. Tamamı Parthlara karşı gönderilen legio I Minervia (Germania inferior), legio II adiutrix (Pannonia inferior), legio V Macedonica (Aşağı Moesia) dışında birçok lejyonun içinden bir kısım birlik vexillatio olarak alınarak doğu cephesine

17 W. Eck, "Die Seuche unter Marc Aurel: Ihre Auswirkungen auf das Heer", L'Impatto della "Peste Antonina", ed. E. Lo Cascio, 2012, s. 63-78.

18 Cassius Dio 71, 2, 4.

19 SHA, Aurelius 12, 9 vd.; Eutropius 8, 10; Grieb 2017, 109 vd.; Michels 2017, 226-235; Der Triumph der Samtherrschaft von 166; Roma'da zafer alayı yapılmasının ideolojik niteliği ve zafer alayı güzergahı hakkında bkz. T. Hölscher, "Die Stadt Rom als triumphaler Raum und ideologischer Rahmen in der Kaiserzeit", Der römische Triumph in Prinzipat und Spätantike, ed. F. Goldbeck - J. Wienand, Berlin 2017, 283-315.

20 A. Marcone, "La peste Antonina Testimonianze e interpretazoni", RSI, 114, 2002, 803-819.

21 SHA, Verus 8, 1- 4; Epitome de Caesaribus 16, 3; Eutropius 8, 12; Hieronymos, chronikon 168 ve 172 y1llar1 olaylar1; Orosios 7, 15, 5 vd.; SHA, Aurelius 13, 3-6; bkz. C. A. Behr, Aelius Aristides and the Sacred Tales, Amsterdam 1968; Publius Aelius Aristides Heilige Berichte, ed. H. O. Schröder, Heidelberg 1986; ayrıca krş. St. Winkle, Eine Kulturgeschichte der Seuchen, Düsseldorf-Zürih 1997, s. 434 vd.; Hatip Aelius Aristeides'in de hieroi logoi (=kutsal sözler) eserindeki nutuklarından birinde (oratio 48, 38) bahsettiği Smyrna (=İzmir) salgını büyük ihtimalle bu salgın olmalıyd1; "Yazın en yakacı günlerini Smyrna'nın kenar semtlerinden birinde geçirdiğim bir sırada tüm komşularım bir bulaşıcı hastalı̆̆a yakalandılar. Önce iki ya da üç hizmetçim hastalandl, daha sonra da bir diğerleri. Sonunda genç-yaşlı herkes yatağa düş̧̈̈. En son hastalanan kişi bendim. Şehir merkezinden gelen hekimler yakinlarina bile hastabakicllk yaptırdllar. Hatta benimle ilgilenen hekimler de birer hizmetçi gibi çalış̧ılar. Bu arada hayvanlar da hastalanmışt. Hastalardan herhangi biri yürümeye kalksa kaplya bile varamadan düşüp ölüyordu. Her yere bir umutsuzluk, feryat, inilti ve çözümsüzlük hakimdi. Şehir merkezinde de aynı korkunç hastalık hüküm sürmekteydi", çeviri için bkz. http://hasanmalay. com/index.php/felsefe/2020-04-25-14-15-19.

22 Roma ordusunda görev yapan askeri doktorlar hakkında en kapsamlı bilgileri Augustus dönemi yazarı olan Gaius Iulius Hyginus'tan (M.Ö. 64 - M.S. 17) öğrenmekteyiz. Hyginus, De munitionibus castrorum 4, 35. Marcus Aurelius bir yasal düzenlemeyle askeri doktorlara vergi muafiyeti getirmiştir; bkz. Digest 50, 6.7 (6). 
gönderilmişlerdi. Parth seferine mevcudlarının bir bölümüyle katılan Pannonia superior eyaletinden legio X Gemina, Tuna sınırından legio VII Claudia, Suriye'den legio III Gallica ve diğer Suriye lejyonları ile Filistin'den legio VI Ferrata ve Mısır'dan bazı birliklerin yanı sıra sayıları tam olarak bilinmeyen çok miktarda yardımcı birliğin de (=auxiliarii) katılmış oldukları anlaşılmaktadır ${ }^{23}$. Sefer bitince bu birliklerin kara yoluyla geri dönüşleri sırasında geçtikleri yerlere hastalığı taşımış oldukları kuvvetle muhtemeldir ${ }^{24}$. Hastalığın Roma lejyonları tarafından önce Anadolu sahiline doğru yayıldı ${ }_{1}^{25}$ ve kısa süre sonra Atina'da etkili olmaya başladığı görülmektedir. Salgın Balkan yarımadasına ve İtalya'ya yayılarak Roma' da hastalanmalara neden olmaya başladı. Bu salgının hangi hastalık olduğu konusunda araştırmacılar farklı görüşler taşımaktadırlar. Asya'dan fareler tarafindan taşınılan veba ${ }^{26}$ ile kolera, tifüs veya çiçek hastalığı bu kavramlarla ifade edilmekteydi. Kaynaklarda salgın hastalık eskiçağ grekçesinde loimos, phthora ya da nosos latin dilinde ise lues, pestis, pestilentia veya plaga kavramlarıyla ifade edilmektedir. Tıp tarihçilerinin yorumlarına göre bu sözcükler her türlü salgın hastalığı tanımlamak için kullanılan kavramlardır ${ }^{27}$. Neredeyse her dört kişiden biri ölmekteydi. Salgın İtalya'dan Gallia'ya (Fransa) ve Hispania (=İspanya) ve hatta deniz aşırı coğrafi konumuna rağmen Britannia’ya kadar yayılmıştı. Tarihi kaynakların bildirdiğine göre birçok bölgenin nüfus yapısı oralarda yerel yönetim birimlerinde görev yapacak uygun aday bulunamayacak kadar bozulmuş ve bu nedenle yerel yönetim görevlerine aday olacaklarda aranılan şartlar kolaylaştırılmıştı ${ }^{28}$. Salgının gerçek boyutlarına ilişkin en kapsamlı bilgileri Mısır papyrusları vermektedir ${ }^{29}$. Salgın öncesi ve salgın sirasında toplanan vergileri belgeleyen listelerin incelenmesi sonucunda da nüfusun dörtte birinin hayatını kaybettiği saptanabilmektedir.

M.Ö. 166 yılında Akdeniz’in tümüne ve Batı Avrupa kadar yayılan salgın eskiçağın en büyük küresel salgınıydı ${ }^{30}$. Daha önceki yüzyıllarda oluştuğu bilinen salgın hastalıkların

23 Suriye eyaletinde konuşlanmış yardımcı birlikler hakkında bkz. P. Weiß, Die Auxilien des syrischen Heeres von Domitian bis Antoninus Pius, Chiron 36, 2006, s. 249-298.

24 Parth savaşına katılan birlikler ve bunların doğu sınırına intikal etmeleri ile doğudan tekrar karargahlarına dönüşleri sırasında temas ettikleri sivil yerleşim yerleri ve bu yolla hastalığın hızla yayılması hakkında bkz. Eck, "Die Seuche unter Marc Aurel: Ihre Auswirkungen auf das Heer", s. 65-66.

25 Manisa'nın Gördes ilçesine bağlı Çiçekli ile Dutluca köyleri arasında bulunan Hyssa adındaki eskiçağ köyünde M.S. 2. yy.da yaşamış olan Flaccus isminde bir köylü kendisini ölümcül bir salgından kurtaran tanrıya orada kaya yüzeyine yazdırdığı bir adak yazıtı ve armağanlar sunmuştu; bkz. http://hasanmalay.com/index.php/ felsefe/2020-04-25-14-15-19.

26 Veba hastalığının fareler tarafından taşındığı arkaik dönemden beri bilindiğinden Apollon sağlık ve veba tanrısı olarak Akdeniz kültürlerinde tapınım görmüş ve bu nedenle yan isimlerinden biri sminthos = fare olarak tanımlanmıştı, bkz. Homeros'un İlias destanı I, 48 vd. ve 450 vd.

27 Bkz. H. Schlange-Schöningen, Die römische Gesellschaft bei Galen, Biographie und Sozialgeschichte, Berlin - New York 2003, s. 145 vd.

28 Eck, "Die Seuche unter Marc Aurel: Ihre Auswirkungen auf das Heer", s. 69.

29 R. Fink, Roman Military Records on Papyrus, Ann Arbor 1971.

30 K. Harper, The Fate of Rome, Climate, Disease and the End of Empire, Princeton/Oxford 2017, 98. Harper boyutları bilinmeyen büyük bir küresel salgın olduğundan emindir. Ancak salgının Afrika bölgesinden İtalya’ya geldiğini yazmaktadır. 
hiçbiri bu kadar geniş bir coğrafi alanda etkili olmamıştı. Ancak daha önceki ve daha sonraki salgınlarda çıkış yeri olarak kaynaklarda hep Avrupa toprakları dışındaki bölgelerin gösterilmesi ilginçtir. M.Ö. 5. yy. sonunda Atina' da görülen salgında, M.S. 2. ve 3. yüzyıllarda görülen ve yıllarca süren salgınlarda da çıkış bölgelerinin Etiopya gibi Avrupa ve Akdeniz havzası uzağındaki bölgeler olarak belirtilmeleri dikkat çekicidir. Marcus Aurelius ve Lucius Verus'un Roma devletini birlikte yönettikleri dönemde ortaya çıkan ve esasen eskiçağın küresel salgını (= pandemisi) olarak da tanımlanabilecek olan bu salgının hızla yayılmasında Roma imparatorluğunun egemenliği altındaki bölgelerin M.S. 2. yy. da ulaştığı yüksek refah düzeyinin büyük rolü vardı. Roma devleti M.Ö. 1. yy. in son çeyreğinden başlayarak tüm Akdeniz bölgesini ve komşu coğrafyaları Roma şehrinden yönetecek merkezi bir yönetim sistemi kurmuş ve imparatorluğun her tarafında hayatın temelini oluşturan şehirleşmeye, ticareti desteklemek amacıyla limanlara ve şehirleri birbirine bağlayan yolların yapımına büyük önem vermişti. O dönem için yoğun nüfusa sahip olan şehirlerde insanlar dar alanda birlikte yaşamaktaydılar. Şehirleri birbirine bağlayan mükemmel birer mühendislik eseri olan yollar ve köprüler ile deniz üzerinden limanlar arasında ulaşımı sağlayan gemiler, bölgelerarası hareketliliği arttırmış ve hızlandırmıştı. Roma imparatorluğu sınırları içinde yaşayan insanların refahı için yapılmış olan bu yatırımlar Roma devletinin egemenliği altında yaşayanlar için ölümcül sonuçlara yol açmaya başlamıştı. Eskiçağın en kapsamlı merkezi yönetim sistemine sahip Roma devleti sağlam eyalet yapısına rağmen bölgelerüstü boyuttaki salgın hastalık karşısında çaresiz kalmıştı. Çünkü bu boyutta geniş bir coğrafyaya yayılan salgınla insanlık daha önce karşılaşmamıştı. Milattan önceki yüzyıllarda İtalya yarımadasında bazı bölgelerde salgın hastalıkların ortaya çıktığını tarihi kaynaklar yazmaktadır ${ }^{31}$. M.S. 2. yy. ın ikinci yarısında ortaya çıkan salgın hastalık sırasında gerçi önce tanrıların öfkesini neden Romalılara yöneltmiş olduğunun nedenleri araştırıld ${ }^{32}$. Tanrıların topluma huzur

31 İmparator Augustus döneminde yaşamış olan tarihçi Titus Livius (M.Ö. 59 - M.S. 17) M.Ö. 3. yy. da İtalya'da bir salgın hastalığın ortaya çıktığını yazmaktadır; bkz. Livius 10, 47, 6. Ancak bu salgının ve diğer yayılan hastalıkların İtalya yarımadası dışına yayılıp yayılmadığı bilinmemektedir. Bu tür çaresiz kalınan durumlarda Roma'da Kapitol tepesindeki tapınakta muhafaza edilen kehanet kitaplarına başvurulmakta ve kehanet kitaplarının tavsiyesi doğrultusunda genellikle Epidauros'ta (Epidauros, Yunanistan'da Mora yarımadası üzerinde Argolis bölgesinde ve Naphlion şehri yakınlarındadır) bulunan sağlık tanrısı Asklepios'un kutsal alanına bir heyet gönderilerek salgının ortadan kalkması için tanrıya yakarılırdı. Livius'un anlattı̆̆ı M.Ö. 292 yılındaki bu olay sırasında da Romalılar çare olarak hemen senatör Quintus Ogulnius Gallus başkanlığında bir heyeti Epidauros'a yolladılar. Heyet sağlık tanrısının sembolü olan bir yılanı alarak Roma’ya döndü. Yılan serbest bırakılınca yüzerek Tiber nehri üzerindeki adacığa çıktı. Bu olayı Romalılar tanrının kendilerine verdiği bir işaret olarak kabul edip Tiber üzerindeki adada sağlık tanrısı için bir tapınak yaptırmaya karar verdiler. Bu olay Romalıların salgınları tıpkı diğer Akdeniz kavimleri gibi tanrılar tarafından üzerlerine gönderilmiş olumsuz olaylar olarak yorumladıklarını ve bu olumsuzluğun ortadan kalkmasını da ancak tanrıların sağlayacağına inandıklarını göstermektedir. M.Ö. 3. yy. başlarında Romalılar henüz tıp ilmine ve tıbbi yöntemleri kullanarak insanları iyileştirmeye çalışanlara güvenmek yerine tanrıların bağışlayıcılığına sığınmayı tercih etmekteydiler.

32 Tanrıların öfkesini Roma'ya yöneltenlerin başında tahta göz diken Avidius Cassius olduğu öne sürülmüştür bu konu hakkında; bkz. SHA, Verus 8, 3; A. Birley, Mark Aurel, Kaiser und Philosoph, München 1977², s. 272274; J. Fündling, Mark Aurel, Darmstadt 2008, s. 95-96. 
sağlaması aynı zamanda baş rahip olan Roma imparatorunun göreviydi ${ }^{33}$. Ancak hemen sonrasında hastalığın kaynağı somut verilere dayanılarak araştırıldığında bu hastalığın ilk olarak Parth'ların Bağdat yakınlarındaki başşehri Ktesiphon’u yağmalayan Romalı lejyon askerlerine bulaşmış olduğu anlaşıldı. M.S. 4. yy.da Ktesiphon'un Romalılar tarafından ele geçirilmesini anlatan Ammianus Marcellinus, Romalı askerlere bu hastalığın Parth kralının ikametinin de bulunduğu yerdeki Apollon Komaeos kutsal alanının yağmalanması sırasında kutsal sayılan bir mahfazanın kırılması ve içindeki ölümcül maddenin yayılmasıyla bulaştığını yazmaktadır ${ }^{34}$. Bu olayın gerçek olup olmadığı bilinmemektedir ${ }^{35}$. Belki Roma'da hastalıktan kırılan Roma halkı bu öyküyü uydurmuş olabilir. Belki de Parthlardan kaynaklanan bir lanetleme hikayesi olarak değerlendirilebilir. Ancak bu hastalık nereden kaynaklanırsa kaynaklansın, çok hızlı yayılmaktaydı ve daha önceki salgınlarda uygulanan tanrılara yakarma, kurbanlar ve çeşitli hediyeler sunma herhangi bir yarar sağlamıyor ve hastalık hızla yayılıyordu.

Roma'da 12 Ekim 166 tarihinde Marcus Aurelius ile Lucius Verus'un birlikte yaptıkları zafer alayından önce başkentte salgın belirtilerinin görüldüğü ve 163 yılından beri Roma'da imparatora çok yakın olan ünlü Bergamalı hekim Galen'in, kölelerinin birbiri ardına ölmeleri nedeniyle Lucius Verus'un Roma'ya ulaşmasından önce salgın nedeniyle Roma'dan ayrılmış olduğu bizzat kendi yazdıklarından anlaşılmaktadır ${ }^{36}$. Galen (M.S. 129199) Bergamalı bir mimarın oğluydu ${ }^{37}$. Bergama'dan sonra Smyrna ve İskenderye'de iyi bir tıp eğitimi aldıktan sonra 157 yılında döndüğü memleketi Bergama' da gladyatör okulunda doktor olarak görev yaptığı sırada anatomi ve özellikle yaralanmalara cerrahi müdahaleler konusunda önemli deneyim kazanmıştı. 163 yılında Roma’ya giden Galen kısa zamanda ünlü bir hekim oldu. S1klıkla hastalıklar yaşayan ve aynı zamanda bir filozof olan imparator Marcus Aurelius, Galen'in tedavi yöntemlerinden başka Hippokrates’in tıp öğretisini daha geliştiren yazılarını da yakından takip etmekteydii ${ }^{38}$ Galen hem Hippokrates’in (M.Ö. 460370) sistemli hale getirdiği teşhis ve tedavi yöntemlerine sadık kalmakta ve hem de yaşadığ 1 dönemdeki hastalıkların seyrine göre kendine özgü yeni teşhis ve tedaviler geliştirmekteydi.

33 Bazı bilim insanları Marcus Aurelius ile Lucius Verus arasındaki rekabetin bu salgına sebep olduğuna inanların sayısının o dönem Roma toplumunda oldukça fazla olduğunu yazmaktadırlar; bkz. Klinkott, s. 298-305; Salgın sırasında Apollon'a yapılan adakların dikkat çekecek düzeyde arttığı görülmektedir, bkz. Harper, s. 101; Ph. Deeg, Der Kaiser und die Katastrophe, Stuttgart 2019, s. 189.

34 Ammianus Marcellinus 23, 6, 24; Deeg, s. 186.

35 Klinkott, s. 301 vd.; Klinkott Ktesiphon'da kutsal bir mahfazanın açılmasıyla yayılan madde anlatımının Pandora mythosuyla özdeşleştirilen uydurulmuş bir öykü olduğu düşüncesindedir. Buna karşın Adams salgının doğudan başladığı tezine katılmaz ancak bu düşüncesinin gerekçesini de belirtmez; G. W. Adams, Marcus Aurelius in the Historia Augusta and Beyond, Lanham 2014, s. 97.

36 PIR $^{2}$ G 24.

37 Galen hakkında bkz. The Cambridge Companion to Galen, ed. R. J. Hankinson, Cambridge 2008; S. Mattern, The Prince of Medicine Galen in the Roman Empire, 2013.

38 Galen'in bizzat yazdığı tahmin edilen içerikleri tıbbi, felsefi ve tıp etiğine yönelik 441 eseri vardır. Bunların listesi hakkında bkz. K. Brodersen, Galen, Stuttgart 2016, s. 40. 
M.S. 166 yılında salgın başladığında yaklaşık 37 yaşında olan Galen Roma' da imparatorun en güvendiği hekimlerin başında gelmekteydi. Ancak imparatorluğun merkezinde birdenbire çok sayıda insan ölmeye başlayınca ve neredeyse yanındaki tüm kölelerini salgın nedeniyle kaybedince Roma'da kalmak yerine hızla başkentten ayrılıp daha güvenli olmamasına rağmen memleketi Pergamon'a (=Bergama) gitti. Fakat Galen'in bu olaya ilişkin anlatımları incelendiğinde onun, Roma'dan salgın başlaması nedeniyle Verus'un Roma'ya gelmesinden önce ayrıldığı anlaşılmaktadır. Yaklaşık iki yıl kaldığı Bergama'dan 168 yılında imparator Marcus Aurelius'un derhal kuzeydoğu İtalya'da Venedik yakınlarında bulunan Aquileia şehrine gelmesini emretmesi üzerine ayrıldı. Marcus Aurelius'un Markoman savaşını yönettiği ana karargâhın bulunduğu Aquileia'ya ulaşan Galen hem imparatoru tedavi etti ve hem de orada hastalığın belirtilerini ve insan vücudundaki tahribatını ayrıntılarıyla gözlemledi ${ }^{39}$. Hastalığın belirtileri olarak ateş, ishal, boğazda iltihap ve hastalığın bulaşmasından dokuz gün sonra deride görülen kabarıklıkları saptadı ${ }^{40}$. Bu saptamaları nedeniyle Marcus Antonius dönemindeki büyük salgın Galen salgını olarak da tanımlanmaktadır ${ }^{41}$. Bazı tıp tarihçileri, Galen'in saptamalarını yorumlayarak çağdaş tıp verileri doğrultusunda bu salgın hastalığın tifüs ya da veba değil daha çok çiçek hastalığı belirtileri olarak yorumlanabileceğini tahmin etmektedirler. Galen ise o dönemdeki tıp bilgisi doğrultusunda solunan havanın kalitesinin bozulmasıyla bu hastalığın oluşmuş olabileceğini tahmin etmektedir. Galen, Aquileia'da imparatorun, ordugâha birlikte gidip orada revirde ${ }^{42}$ yatan hastalanmış olan askerleri ayrıntılı bir şekilde tedavi etmesi isteğini rüyasında tanrı Asklepios’un kendisine görünerek askeri seferlere katılmasını yasakladığı gerekçesiyle reddetti ${ }^{43}$. Marcus Aurelius bu gerekçeyi kabul etti ve birlikte Roma'ya giderek imparatorun oğlu Commodus'un boğazındaki iltihaplanmayı tedavi etti ${ }^{44}$. Galen, Roma'daki ağır havanın hastalığın nedenlerinden biri olabileceğini düşünmektedir. Marcus Aurelius'un da solunan havanın çok kirli ve ağır olduğunu söylemiş olduğunu tarihi kaynaklar yazmaktadır. Marcus Aurelius'un oğlu Commodus, hekim Galen'in bu değerlendirmesinin o kadar etkisinde kalmıştır ki Roma'daki ikametgâhını terk etmiş ve Latium bölgesinde bulunan Laurentum' daki villasına giderek orada temiz havada defne ağaçlarının kokusunun kendisine iyi geleceğini düşünmüştür. Roma şehrinde yaşayanların ise böyle bir imkanları yoktu. Sadece kulak ve burunlarına sürdürdükleri güzel kokulu merhemlerle kendilerini korumaya çalışmaktaydılar. Bu yöntemin hiçbir faydasının olmadığı, çaresiz bir şekilde insanların

39 Galen 19, 18 K = Scripta Minora II 98; H. G. Schmitt, Die Pest des Galenos, Würzburg 1936; P. Moraux, Souvenir d'médecin: Galien de Pergame, Paris 1985, s. 17.

40 Galen 19 Cassius Dio 72, 14, 3 Herodian I, 12

41 Galen'in teşhisleri, tedavi yöntemi önerileri ve can kaybı hakkında bkz. R. J. Littmann - M. L. Littmann, "Galen and the Antonine Plague", AJPh, 94, 3, 1973, s. 243-255.

42 Roma ordugahlarını askeri hastahaneleri $=$ valetudinaria exercitus ve sahada kurulan revirleri hakkında bkz. Seneca, de ira I, 16, 4.

43 Galen 9.

44 Galen 14 
ölümlerini izlemekten başka doktorların ellerinden bir şeyin gelmediği anlaşılmaktadır ${ }^{45}$. Sadece Roma şehrinde kaç kişinin öldüğü tam olarak bilinmese de sayının çok yüksek olduğu tahmin edilmektedir ${ }^{46}$. Kimsesizlerin ve kölelerin ölmeleri halinde cesetleri yolun kenarına atılmakta ve yeni bulaşıcı hastalıkların oluşması tehlikesi yaratmaktaydılar ${ }^{47}$. Durumu iyi olanlar yüksek toplumsal tabakaların mensupları ise onurlandırılarak törenle defnedilmekteydiler ${ }^{48}$. Marcus Aurelius üst toplumsal tabakalarla ve senatörlerle gerginlik yaşamamak için onlardan ölenleri Roma devleti hizmetinde ölmüş gibi yücelterek devlet töreniyle defnedilmelerine imkân tanıyan düzenlemeler yapmıştır ${ }^{49}$. Yakınlarını kendi imkanlarıyla ve geniş katılımla defnedemeyenlere devletin yardım etmesini, defin ekipleri kurarak yollarda defnedilemeden bırakılanları özel yapılmış arabalarla taşıtarak bu definler için belirlenmiş yerlere defnedilmeleri için yasal düzenlemeler yapmışt ${ }^{50}$. Definlerin Roma çevresinde tarıma elverişli arazilere yapılmasına izin verilmemekteydi. Marcus Aurelius bunlardan başka imparatorluğun her tarafında rahiplerin tanrılara yardım etmeleri için yakarmalarını, arınma törenleri düzenlemelerini ve Roma dini dışındaki dinlerin inanç dünyasından da yararlanılabilecek ritüellere başvurmalarını emretmiştir ${ }^{51}$.

Salgının yayıldığı coğrafi alanın genişliği ve yıllarca sürmesi Roma imparatorluğu sınırları içindeki nüfus yapısını önemli ölçüde değiştirmiş olmalıydı ${ }^{52}$. Salgının Roma dışında eyaletlerde ne kadar can kaybına sebep olduğu bilinmemektedir. Galen'in memleketi Bergama'da da ağır kayıplar olduğu ve Asklepion'da 17 yıl tedavi gördükten sonra 181 yılında hayatını kaybeden ünlü Mysia'lı hatip Aelius Aristides'in de Anadolu'da bu salgının devamı kabul edilen salgınlardan birinde ölmüş olabileceği tahmin edilmektedir ${ }^{53}$. Büyükbaş ve küçükbaş hayvanların da salgından etkilendikleri bildirilmektedir. Atina'da da ağır kayıplar olduğu anlaşılmaktadır. Tarihi kaynakların kaydettiği M.S. 2. yy.ın son çeyreğinde ortaya çıkan salgınların 166 yılında başlayan bu salgının devamı mı yoksa bu salgından

45 J. Kobes, "Pest in der hohen Kaiserzeit"; Pest Die Geschichte eines Menscheittraumes, ed. M. Meier, Stuttgart 2005, s. 76; H. Sonnabend, Katastrophen der Antike, Darmstadt 2013, s. 50; Harper, s. 98.

46 J. Greenberg, "Plagued by doubt: reconsidering the impact of a mortality crisis in the 2nd c. A.D.", JRA, 16, 2003, s. 413-425.

47 Fündling, a.g.e., s. 96.

48 Bu konu SHA Aurelius 13, 3-6; Birley, a.g.e., s. 274 ve dipnot 38'de Marcus Aurelius'un hayatının anlatıldığ1 Scriptores Historiae Augustae'da verilen bilgileri ayrıntılı bir şekilde yorumlar. Buna karşın Adams, salgının doğudan başladığı tezine katılmaz ancak bu düşüncesinin gerekçesini de belirtmez (a.g.e., s. 97).

49 SHA Aurelius 13, 3 vdd. 17, 2.

50 J. Toner, Roman Disasters, Cambridge/Malden 2013, s. 53 vd.

51 SHA Aurelius 13, 1.

52 Bazı araştırmacılar salgının şiddetinin abartıldığını düşünmektedirler, bunun için bkz. F. J. Gilliam, “The Plague under Marcus Aurelius", AJP, 82, 1961, s. 225-251.

53 Bkz. Klinkott, s. 297; ayrıca krş. Chr. P. Jones, “Aelius Aristides and the Asklepion”, Pergamon: Citadel of the Gods, ed. H. Koester, Harvard Theological Studies, 46, 1998, s. 63-76; Aristides'in Marcus Aurelius ve Lucius Verus dönemine ilişkin nutukları ve Bergama'da gördüğü tedavi süreci hakkındaki bilgiler için bkz. Demandt, Marc Aurel, s. 164-166. 
bağımsız mı geliştikleri de bilinmemektedir ${ }^{54}$. Kesin olan ise; bu salgının 166 yılından 170 yılına kadar şiddetini azaltmadan devam etmiş olduğudur ${ }^{55}$. Yedi yıl boyunca yoğunluğu oldukça azalan salgının 177 yılında yeniden hızlanarak kitlesel ölümlere yol açtığı ve bunun 180 yılından sonra azalmaya başladığı düşünülmesine rağmen bazı tarihçiler 189 yılında Commodus döneminde çok büyük bir salgının Roma’ya kadar yayıldığını yazmaktadırlar ${ }^{56}$. Roma şehrinde salgın döneminde günde 2.000 kişinin hayatını kaybettiğinden Nikaia'lı (İznik) tarihçi Cassius Dio bahsetmektedir ${ }^{57}$.

M.S. 162 ile 166 yılları arasında yapılan Parth seferini yöneten Lucius Verus M.S. 169 yılı başında Aquileia'dan Roma'ya giderken Altinum'da 39 yaşında öldü. Marcus Aurelius ise Tuna sınırını korumaya çalışırken M.S. 180 yılında Sirmium yakınlarında Bononia'da -bazı tarihçilere göre Vindobona'da (=Viyana'da)- 60 yaşında öldü ${ }^{58}$. Her iki imparatorun da salgın hastalık nedeniyle ölüp ölmedikleri halen sorgulanmaktadır ${ }^{59}$. Salgının sosyal ve ekonomik etkileri ise Roma imparatorluğu için çok yıkıcı oldu. Büyük insan kaybı nedeniyle işgücü eksilmesiyle şehirlerdeki ekonomik hayat ve kırsal kesimdeki zirai faaliyetler olumsuz etkilendi. Bölgelerarası ticari hareketlilik büyük ölçüde kesintiye uğradı. M.S. 2. yy.ın ikinci yarısındaki bu salgının Roma imparatorluğunun tüm eyaletlerine yayıldığı, hatta Barbaricum olarak tanımlanan Roma sınırları dışındaki bölgelerde de etkili olduğu anlaşılmaktadır. Ancak bu bölgelerde yoğun yerleşim ve fazla insan hareketliliği olmamasından ötürü can kayıplarının fazla olmadığı tahmin edilmektedir. Tarih boyunca görülmüş büyük salgınlardan hiçbiri Marcus Aurelius dönemindeki kadar büyük bir coğrafyayı bu kadar ağır kayıplarla

54 Bazı araştırmacılar birbirlerinden bağımsız gelişen yerel salgınların tüm Roma imparatorluğuna yayılmış olduğunu düşünmektedirler. Klinkott, s. 289.

55 Duncan-Jones 1996 yılında yazdığı bir makalede salgının 165 yılından sonra da devam ettiğini insanların ihtiyaçlarının temin edilmesi için gerekli tedarik zincirinin ve üretimin düşmesini pişmiş toprak kapların üretim yoğunluğu ve sikkeler üzerinden yorumlamaya çalışmaktadır. R. P. Duncan-Jones, "The Impact of Antonine Plague", JRA , 9, 1996, 108-136. Bazı araştırmacılar bu sonucun amphora buluntularının farklı bölgelerde farklı yoğunluklar göstermesi nedeniyle gözden geçirilmesi gerektiğini yazmaktadır, bkz. Ehmig, 1998, 206-208; Duncan-Jones 1996'da ortaya koyduğu saptamaları 2018 yılında yazdığı bir makaleyle salgının yayılma alanı ve süresine kadar daha ayrıntılı bir şekilde değerlendirmektedir. R. P. Duncan-Jones, "The Antonine Plague", Arctos Revisited, 52, 2018, s. 41-72.

56 Cassius Dio 72, 14, 3; Herodian I 12.

57 Cassius Dio 71, 2, 4; Fündling, a.g.e., 95 vd.

58 Cassius Dio, imparator Marcus Aurelius'un salgın hastalığa yakalanması nedeniyle öldüğünü yazar; Cassius Dio 72. 33. 4; Scriptores Historiae Augustae'da Marcus Aurelius hayatını anlatan anonim biograf, imparatorun ölümünden çok sayılamayacak kadar çok insanın ölmesine üzülmek gerektiğini yazmaktadır; SHA 28,4; D. Pausch, "Der Philosoph auf dem Kaiserthron, der Leser auf dem Holzweg?", Marc Aurel in der Historia Augusta in Millenium, 4, 2007, 107-155; Sonnabend, s. 120; Adams, s. 125; Deeg, s. 190.

59 Marcus Aurelius'un hastalığı hakkında bkz. SHA, Aurelius 28, 1; Herodian 1, 3, 1; Orosios 7, 15, 12; Marcus Aurelius'un hastalığının 166'da başlayan ve yıllarca devam eden salgınla bağlantılı olduğu öne sürülmektedir; bkz. Sonnabend, s. 51 ve 119; Birley, s. 378 vd. Marcus Aurelius’un ölüm döşeğinde kendisinin ölümüne değil salgının kurbanlarına ağlamaları gerektiğini söylerken, kendisinin onlardan biri olmadığını ifade etmesi doğrudan salgınla ilişkili bir hastalıktan ölmediğinin belgesi olarak kabul edilmektedir, s. SHA Aurelius 28, 4. 
etkilememişti ${ }^{60}$. Marcus Aurelius'un salgın nedeniyle giderek sayıları azalan askeri birliklerin kayıplarını gidermek için aldığı askere alma önlemleri ile Atina'da Areopag'a seçilebilmek için üç yıl önce getirmiş olduğu üç nesil öncesine kadar ailesinin fertlerinin özgür vatandaş olmalarının aranması için kendi yaptığı düzenlemeyi kaldırmak zorunda kalması hem askeri birliklerde ve hem de sivil halkta çok ciddi kayıpların olduğunu, birçok kimsenin ailesinin üç nesil oluşturmasının salgın nedeniyle oluşan kayıplardan ötürü mümkün olamadığını göstermektedir ${ }^{61}$. Bu durum Marcus Aurelius dönemindeki salgında oluşan kayıpların kesinlikle abartılmadığını oldukça yüksek can kaybı olduğunu, imparatorluğun sınırları içerisindeki demografik yapının önemli ölçüde etkilendiğini ve hastalığın yarattığı tahribatın dönemin kaynaklarında da belirtildiği gibi yıllarca sürdüğünü ortaya koymaktadır. Ne M.Ö. 430/429 yılında Atina ve çevresinde görülen salgının ve ne de M.S. 248 yılında Roma imparatorluğunda görülen ve Decius ya da Kyprianos salgını olarak tanımlanan hastalığın yayıldığı alan bu kadar büyük değildi ve bu kadar yüksek sayıda can kaybı yoktu. 6. yy.da Justinianus döneminde dalgalar halinde yayılan ve Justinianus vebası olarak tanımlanan veba salgını yıllarca kitlesel ölümlere neden olmuş ve neredeyse Ortaçağda görülen büyük veba salgınları gibi o zaman için bilinen dünyanın nüfus yapısının değişmesine neden olacak ağır can kayıpları meydana gelmişti. 19. yy.da bazı eskiçağ tarihçileri bu salgının yarattı̆̆ yıkıcı etkinin Roma imparatorluğunun 3. yy.da yaşadığı, siyasi, askeri ve iktisadi krizin hazırlayıcısı olduğunu hatta eskiçağın bitimi olarak yorumlanabileceğini öne sürmektedirler ${ }^{62}$. Ancak Roma imparatorluğunun 3. yy.da yaşadığı krizin 2. yy.ın ikinci yarısındaki büyük salgının yarattığ 1 olumsuzluklardan başka nedenleri de vard ${ }^{63}$. Nitekim 20 . yy. tarihçileri tüm yıkıcı etkilerine rağmen Marcus Aurelius dönemindeki salgının Roma imparatorluğunun ve eskiçağın sonu olarak yorumlanamayacağını belirtmektedirler ${ }^{64}$.

60 Marcus Aurelius'un asker mevcudunun salgın nedeniyle hızla azalmasına karşı aldığı̈ önlemlerin gerekliliğinin ve ne ölçüde faydalı olduklarının mezar yazıtları, askeri birliklerin onurlandırma listeleri ve askeri diplomalar vasitasıyla belirlenmeleri hakkında bkz. Eck, "Die Seuche unter Marc Aurel: Ihre Auswirkungen auf das Heer", s. 68-76.

61 Bu konu hakkında bkz. Chr. P. Jones, "Recruitment in time of plague: the case of Thespiae", L'Impatto della "Peste Antonina", ed. E. Lo Cascio, 2012, s. 83.

62 Bu görüşler hakkında bkz. B. G. Niebuhr, Vorträge über Alte Geschichte II (1825), 1848, s. 65; O. Seeck ise imparatorluğun nüfusunun neredeyse yarısının hayatını kaybettiğini belirterek ordunun mevcudunun da büyük ölçüde azaldığını ve askeri gücünü kaybeden Roma devletinin çöktüğünü düşünmektedir, O. Seeck, Geschichte des Untergangs der antiken Welt, Stuttgart I, 1895, s. 398.

63 Bkz. Chr. Bruun, "The Antonine Plague and the ,Third-Century Crisis", Crises and the Roman Empire. Proceedings of the Seventh Workshop of the International Network Impact of Empire (Nijmegen, June 20-24, 2006), ed. O. Hekster - G. de Kleijn - D. Slootjes, Leiden 2007, s. 201-217.

64 Gilliam, a.g.m., s. 160; Birley, s. 272, 352 vd.; A. Demandt, Der Fall Roms, Münih 2014, s. 292; Klinkott, s. 285-305. 
Hakem Değerlendirmesi: Dış bağımsız.

Çıkar Çatışması: Yazar çıkar çatışması bildirmemiştir.

Finansal Destek: Yazar bu çalıșma için finansal destek almadığını beyan etmiștir.

Peer-review: Externally peer-reviewed.

Conflict of Interest: The author has no conflict of interest to declare.

Grant Support: The author declared that this study has received no financial support.

\section{Kaynakça/References}

Adams, G. W., Marcus Aurelius in the Historia Augusta and Beyond, Lanham 2014.

Barnes, T. D., "Hadrian and Lucius Verus", JRS, 57, 1967, 65-79.

Behr, C. A., Aelius Aristides and the Sacred Tales, Amsterdam 1968.

Birley, A., Mark Aurel, Kaiser und Philosoph, München $1977^{2}$.

Bishop, M. C., Lucius Verus and the Roman Defence of the East, South Yorkshire 2018.

Bowersock, G., "Lucius Verus in the Near East", Rome et ses provinces. Génèse et diffusion d'une image du pouvoir, ed. C. Evers - A. Tsingarida, Hommage à J.-Ch. Balty, Bruxelles 2001, s. 73-77.

Brodersen, K., Galen, Stuttgart 2016.

Bruun, Chr., "The Antonine Plague and the ,Third-Century Crisis", Crises and the Roman Empire. Proceedings of the Seventh Workshop of the International Network Impact of Empire (Nijmegen, June 20-24, 2006), ed. O. Hekster - G. de Kleijn - D. Slootjes, Leiden 2007, s. 201-217.

Deeg, Ph., Der Kaiser und die Katastrophe, Stuttgart 2019.

Demandt, A., Der Fall Roms, Münih 2014. , Marc Aurel, Der Kaiser und seine Welt, Münih 2018.

Duncan-Jones, R. P., “The Antonine Plague”, Arctos Revisited, 52, 2018, 41-72. , "The Impact of Antonine Plague”, JRA, 9, 1996, 108-136.

Eck, W., "Die Seuche unter Marc Aurel: Ihre Auswirkungen auf das Heer", L'Impatto della "Peste Antonina”, ed. E. Lo Cascio, 2012, 63-78.

Edwell, P., Between Rome and Persia, The Middle Euphrates, Mesopotamia and Palmyra under Roman Control, London 2008.

Ehmig, U., "Die Auswirkungen der Pest in antoninischer Zeit”, ZPE 122, 1998, 206-208.

Fink, R., Roman Military Records on Papyrus, Ann Arbor 1971.

Fündling, J., "Lucius Verus, Seine Lobredner, seini Kritiker und sein Platz in der Herrschaft"; Studien zur antiken Geschichtsschreibung, ed. M. Rathmann, Antiquitas 1. 55. Bonn 2009, 211-236.

, Mark Aurel, Darmstadt 2008.

Gebhardt, A., "Imperiale politik und provinziale Entwicklung. Untersuchungen zum Verhältnis von kaiser Heer und Städten im syrien in vorseverischer Zeit", Klio Beiheft, Neue Folge 4, Berlin 2002.

Gilliam, F. J., “The Plague under Marcus Aurelius”, AJP, 82, 1961, 225-251. 
Greenberg, J., "Plagued by doubt: reconsidering the impact of a mortality crisis in the 2nd c. A.D.", JRA, 16, 2003, 413-425.

Harper, K., The Fate of Rome, Climate, Disease and the End of Empire, Princeton/Oxford 2017.

Hölscher, T., "Die Stadt Rom als triumphaler Raum und ideologischer Rahmen in der Kaiserzeit", Der römische Triumph in Prinzipat und Spätantike, ed. F. Goldbeck - J. Wienand, Berlin 2017, 283-315.

Jones, Chr. P., “Aelius Aristides and the Asklepion”, Pergamon: Citadel of the Gods, ed. H. Koester, Harvard Theological Studies, 46, 1998, 63-76.

, "Recruitment in time of plague: the case of Thespiae", L'Impatto della "Peste Antonina", ed. E. Lo Cascio, 2012, 79-85.

Klinkott, H., "Parther-Pest-Pandoramythos. Katastrophen und ihre Bedeutung für die Regierungszeit von Marc Aurel"; Marc Aurel Wege zu seiner Herrschaft, ed. V. Grieb, Gutenberg 2017, 285-305.

Kobes, J., "Pest in der hohen Kaiserzeit"; Pest Die Geschichte eines Menscheittraumes, ed. M. Meier, Stuttgart 2005.

Littmann R. J. - M. L. Littmann, “Galen and the Antonine Plague”, AJPh, 94, 3, 1973, 243-255.

Marcone, A., "La peste Antonina Testimonianze e interpretazoni”, RSI, 114, 2002, 803-819.

Mattern, S., The Prince of Medicine Galen in the Roman Empire, 2013.

Michels, Chr., “Antoninus Pius und die Rollenbilder des Römischen Princeps”, Klio Beiheft, No. 30, Berlin 2018. , "Sieg und Triumph in der Zeit von Antoninus Pius bis Commodus", Der römische Triumph in Prinzipat und Spätantike, ed. F. Goldbeck - J. Wienand, Berlin 2017, 215-253.

Moraux, P., Souvenir d'médecin: Galien de Pergame, Paris 1985.

Niebuhr, B. G., Vorträge über Alte Geschichte II (1825), 1848.

Pausch, D., "Der Philosoph auf dem Kaiserthron, der Leser auf dem Holzweg?", Marc Aurel in der Historia Augusta in Millenium, 4, 2007, 107-155.

Publius Aelius Aristides Heilige Berichte, ed. H. O. Schröder, Heidelberg 1986.

Schippmann, K., Grundzüge der parthischen Geschichte, Darmstadt 1980.

Schlange-Schöningen, H., Die römische Gesellschaft bei Galen, Biographie und Sozialgeschichte, Berlin New York 2003.

Schmitt, H. G., Die Pest des Galenos, Würzburg 1936.

Scriptores Historiae Augustae (SHA).

Seeck, O., Geschichte des Untergangs der antiken Welt, Stuttgart I, 1895.

Sonnabend H., Katastrophen der Antike, Darmstadt 2013.

Strobel, K., "Zeitgeschichte unter den Antoninen Die Historiker des Partherkrieges des Lucius Verus", Aufstieg und Niedergang der römischen Welt. Geschichte und Kultur Roms im Spiegel der neueren Forschung, ed. Wolfgang Haase, Teil II: Principat, Band 34/2 Berlin 1994, 1315-1360.

The Cambridge Companion to Galen, ed. R. J. Hankinson, Cambridge 2008.

Toner, J., Roman Disasters, Cambridge/Malden 2013.

Weiß, P., Die Auxilien des syrischen Heeres von Domitian bis Antoninus Pius, Chiron 36, 2006.

Winkle, St., Eine Kulturgeschichte der Seuchen, Düsseldorf-Zürih 1997.

Ziegler, K. H., Die Beziehungen zwischen Rom und dem Partherreich. Ein Beitrag zur Geschichte des Völkerrechts, Wiesbaden 1964. 


\section{Ek}

M.S. 2. yy.da Anadolu, Yakın Doğu, Balkanlar, Orta ve Doğu Akdeniz

Anna Maria Wittke - E. Olshausen - R. Szydlak, Historischer Atlas der antiken Welt, Der Neue Pauly Supplemente, c. III, Stuttgart 2007.

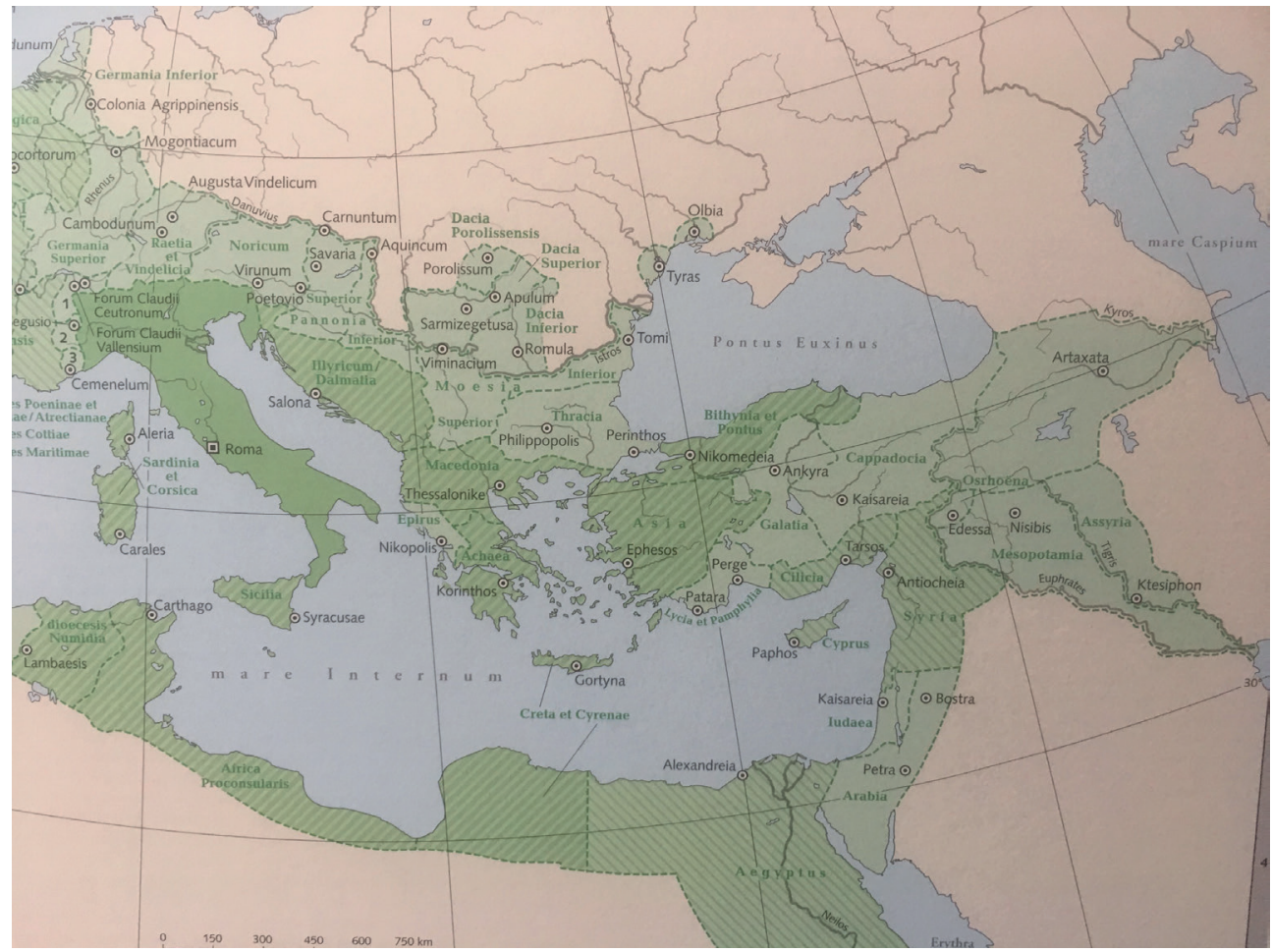

